\title{
Dr. Jessie Wright: Breaking New Ground in Pediatric Physical Medicine and Rehabilitation
}

\author{
Michael Alexander, MD, Margaret A. Turk, MD, Rita Ayyangar, MD
}

\section{INTRODUCTION}

Any history of the growth and acceptance of physical medicine and rehabilitation (PM\&R) as a medical specialty in the United States must include an appreciation of the barriers to and rise of women in medicine. Both histories actually began in the 19th century. Prosthetics were developed for survivors of amputations in the Civil War in the mid to late 1800s, and the American electrotherapy medical societies of the 1890s presaged the development of the physical therapeutics of modern musculoskeletal medicine [1]. The mid 19th century also was an historic time for women in medicine. Elizabeth Blackwell, the first woman to receive a medical degree in the United States, graduated from the Geneva Medical College (now the State University of New York Upstate Medical University) in 1849 and overcame, at least to some extent, the prejudicial attitudes and barriers for women in medicine [2].

The history of PM\&R has always been tied to major wars, and, therefore, further developments within the medical specialty were actually made possible by World Wars I and II, and by others that followed. For pediatric rehabilitation, the polio epidemic in the mid 21 st century was a major contributor to the growth of the specialty. Physical medicine eventually was recognized as a specialty in 1947, with the addition of rehabilitation to the name in 1949. Jessie Wright, MD, was a charter member of the American Society of Physical Medicine, and she was the no. 82 certificant of the American Board of Physical Medicine when it was recognized by the American Medical Association in 1947. Of the first 100 certificants of the American Board of Physical Medicine and Rehabilitation (ABPMR), the number required for recognition of the field as a medical specialty and its certifying board, 5 were women, a number that closely approximated the percentage of women in medicine at the time. Whereas physiatrists became recognized as medical physicians for disability care, women were not welcomed into the "house of medicine" in greater numbers until the 1970s [3].

Wright was recognized during her lifetime as an outstanding physician who made extraordinary contributions to the field of $P M \& R$. Her accomplishments are more extraordinary because she was a female physician practicing in an era when women had to confront attitudes and barriers and surpass the expectations of their male colleagues. She was an academic physiatrist who was also an inventor of the rocking bed for the respiratory management of children and adults with poliomyelitis, and a major physiatric leader, locally, nationally, and internationally (Figure 1).

\section{EARLY CHOICES AND COINCIDENCES}

Jessie Wright, MD, was born on September 5, 1900, in England, where her father was head master of a church school in Eccleshall. When she was 6 years old, she immigrated with her family to the Pittsburgh, Pennsylvania area, where she trained and practiced medicine. Known as "JW" by friends and colleagues, she clearly benefited from a number of long-term relationships with Pittsburgh medical institutions and medical professionals. While she was still a teenager, Wright provided therapeutic exercises and care for a friend whose father was associated with the D. T. Watson Home for Crippled Children, a facility for the care of children with disabilities in the Pittsburgh area (renamed the D. T. Watson Rehabilitation Hospital and, in 2013, The Watson Institute). Wright both trained and practiced medicine at the institution throughout her entire career [4].

M.A. Pediatrics and Physical Medicine and Rehabilitation, Thomas Jefferson University, Philadelphia, PA

Disclosure: nothing to disclose

M.A.T. Department of Physical Medicine and Rehabilitation, State University of New York Upstate Medical University, Syracuse, NY. Address correspondence to: M.A.T.; e-mail: turkm@upstate.edu

Disclosure related to this publication: nothing to disclose

Disclosures outside this publication: grants, Centers for Disease Control 1U01DD00100701: Coordinating Center for Research and Training to Promote the Health of People with Developmental and Other Disabilities; travel/ accommodations/meeting expenses, World Bank, program for staff about Disability Health and Rehabilitation: other, coeditor, Disability and Health Journal, Elsevier Inc., Sage Reference Series on Disability 2013

R.A. Department of Physical Medicine and Rehabilitation, University of Michigan, Ann Arbor, MI

Disclosure related to this publication: nothing to disclose

Disclosures outside this publication: board membership, AAPM\&R Board of Governors 


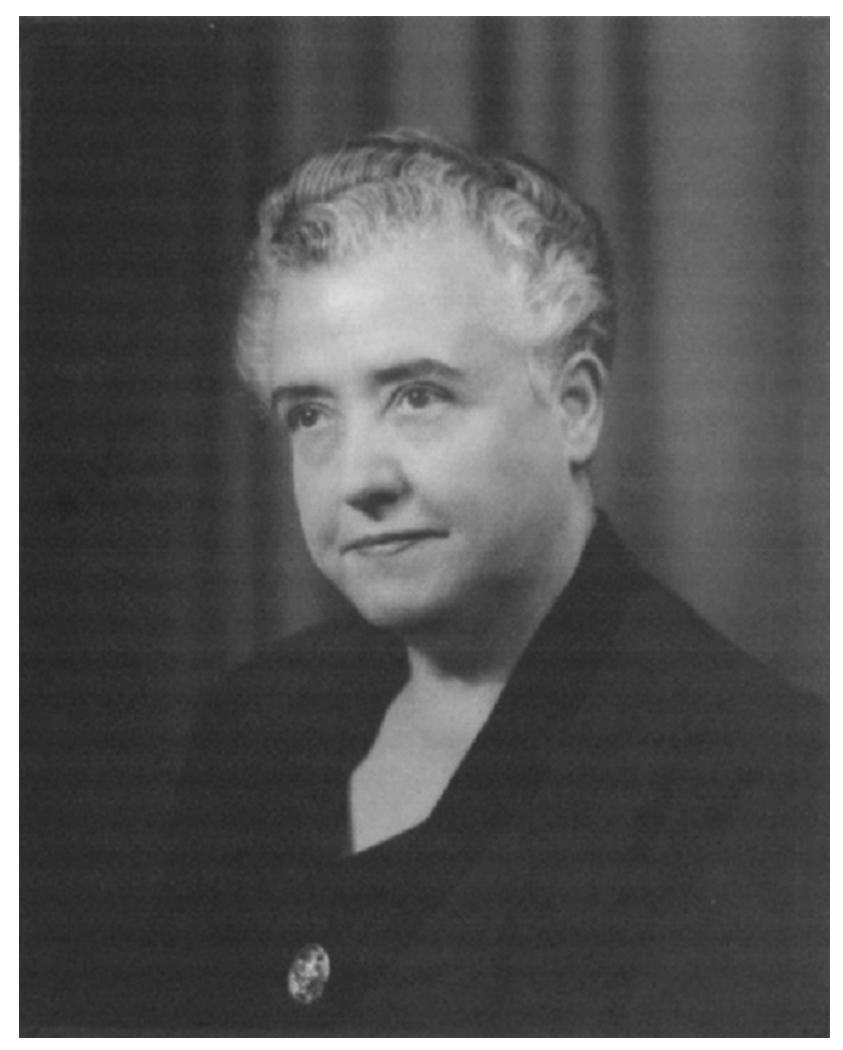

Figure 1. Jessie Wright, MD. Courtesy of Susan L. Whitney, University of Pittsburgh.

Training in the health professions in the 1920s was not organized as it is today, so Wright's work at the D. T. Watson Home began in 1920 where she gained hands-on experience in a variety of roles. She gained first-hand knowledge about hospital and outpatient care, including physical therapy and nursing. The first director of nursing taught her direct bedside care, such as positioning, wound care dressing changes, and preventive care. The first director of physiotherapy, who received training during World War I, taught her valuable lessons about the care of wounded soldiers, including the incorporation of concepts of self-worth and quality of life.

In 1922 and 1924, Wright attended summer physiotherapy seminars at Harvard Medical School. She became chief of physiotherapy at the D. T. Watson Home after returning from the 1922 seminar. Wright began developing an accredited training program in physiotherapy in 1924, and, by 1927, this program was formally established and affiliated with the University of Pittsburgh. In 1927, the program received state approval from the Commonwealth of Pennsylvania, and Wright became a licensed physical therapist that same year. Wright also developed a department of physical therapy at the Children's Hospital of Pittsburgh [5].

Wright then attended the University of Pittsburgh, attaining a bachelor of science degree in 1932, while simultaneously taking courses at the medical school. She received a medical degree in 1934 from the university. She completed an internship at Allegheny General Hospital in Pittsburgh with an emphasis on nonoperative orthopedics and received a license to practice medicine in 1935. The same year, she was appointed the director of physical medicine at 3 Pittsburgh medical institutions: The Children's Hospital; the D. T. Watson Home; and the Municipal Hospital, an acute hospital for patients with poliomyelitis. In 1945, Wright also became the director of physical medicine at Western State Psychiatric Hospital [5]. She also was appointed the director of the D. T. Watson School of Physiotherapy (later called the D. T. Watson School of Physiatrics), a position she held throughout her career until 1966 when she retired [4].

\section{KEY MALE MENTORS AND ASSOCIATES}

Wright's wide-ranging professional activities in these many institutions led to many interactions with other major contributors to the emerging field of PM\&R who became her mentors, supporters, and colleagues. One of these was Oliver Wylie, who served on the first board of directors of the D. T. Watson Home and who was the father of her friend who was diagnosed with poliomyelitis. She spent significant time at the Wylie home, and there she met David Silver, MD, a noted orthopedist and faculty member at the University of Pittsburgh School of Medicine, who also was the medical director of the D. T. Watson Home. In the summers during her medical training, Silver taught Wright orthopedic procedures, such as fracture reduction, joint aspiration, and cast application, and also strapping for joint dislocations. Upon graduation, her initial appointment at the University of Pittsburgh was in the orthopedics department, where she was recognized as competent to perform surgical procedures. She was an anatomy instructor for medical and physical therapy students at Pittsburgh during the first decade of her career [4].

When she attended summer courses in physiotherapy at Harvard Medical School, Wright had the opportunity to study with the orthopedist Frank Ober, MD. Ober is remembered for his observations on the kinesiologic consequences of tight tensor fascia lata, and his eponymous maneuver for tensor fascia lata tightness. At Harvard, she also studied with Frank Granger, MD, a leader in electrical testing and therapy for muscle retraining, who also taught her the application of $P M \& R$ principles to ameliorate the disabling effects of injuries of wounded soldiers [4].

Another important physician and faculty member at the University of Pittsburgh School of Medicine during this period was Jonas Salk, MD, who was developing a vaccine for poliomyelitis. Since the early 1900s, the polio virus had been emerging as the most common infectious etiology of disability in the United States, and the epidemic reached its peak in 1952, the year in which 57,000 adults and children were diagnosed with the disease [6]. The D. T. Watson 
Home had been admitting young adults and children with subacute illness and a need for continuing rehabilitation since it opened. Salk and Wright were natural partners in the endeavor to conquer this disease and its disabling consequences (Figure 2) [6].

David Thomas Watson, a U.S. Circuit Court of Appeals judge, founded the D. T. Watson Home in 1920. Watson did not have children of his own, and his trust established a home for children with disabilities with multifaceted goals: to care for children with disabilities, to prepare them for careers and lives in society, and (as later interpreted by the board of directors) to establish a physical therapy training program [4]. Wright was able to take advantage of the missions of the D. T. Watson Home, especially with the backing of David Silver.

\section{PEDIATRIC PM\&R}

The D. T. Watson Home was situated in a beautiful setting on a hill overlooking the Ohio River in Leetsdale, Pennsylvania, where patients were residents and lived on the grounds for long periods of time. The bucolic setting allowed for therapeutic recreational activities, such as golf, skiing, or horticultural pursuits, which enhanced the treatment of psychological effects of disability and promoted quality of life and functioning. The hospital admitted patients recently diagnosed with polio, including the most complex cases that involved respiratory effects and severe paralysis. Children constituted the majority of residents of the home. The environment and the goals of treatment reflected Wright's philosophy of the value of promoting self-worth and preparing patients to direct and ultimately provide self-care.

Wright also was actively involved in the care and rehabilitation of children with cerebral palsy [7]. She organized several clinics for children with cerebral palsy in Pittsburgh and four western Pennsylvania counties (Beaver, Indiana, Somerset, Wetsmoreland). Wright invented several therapeutic devices, including standing tables, stretching devices, and weighted "bracelets" to control dyskinesias in children with cerebral palsy, and developed therapeutic techniques to promote their independence [4]. She also was active in training programs for this population, participating in

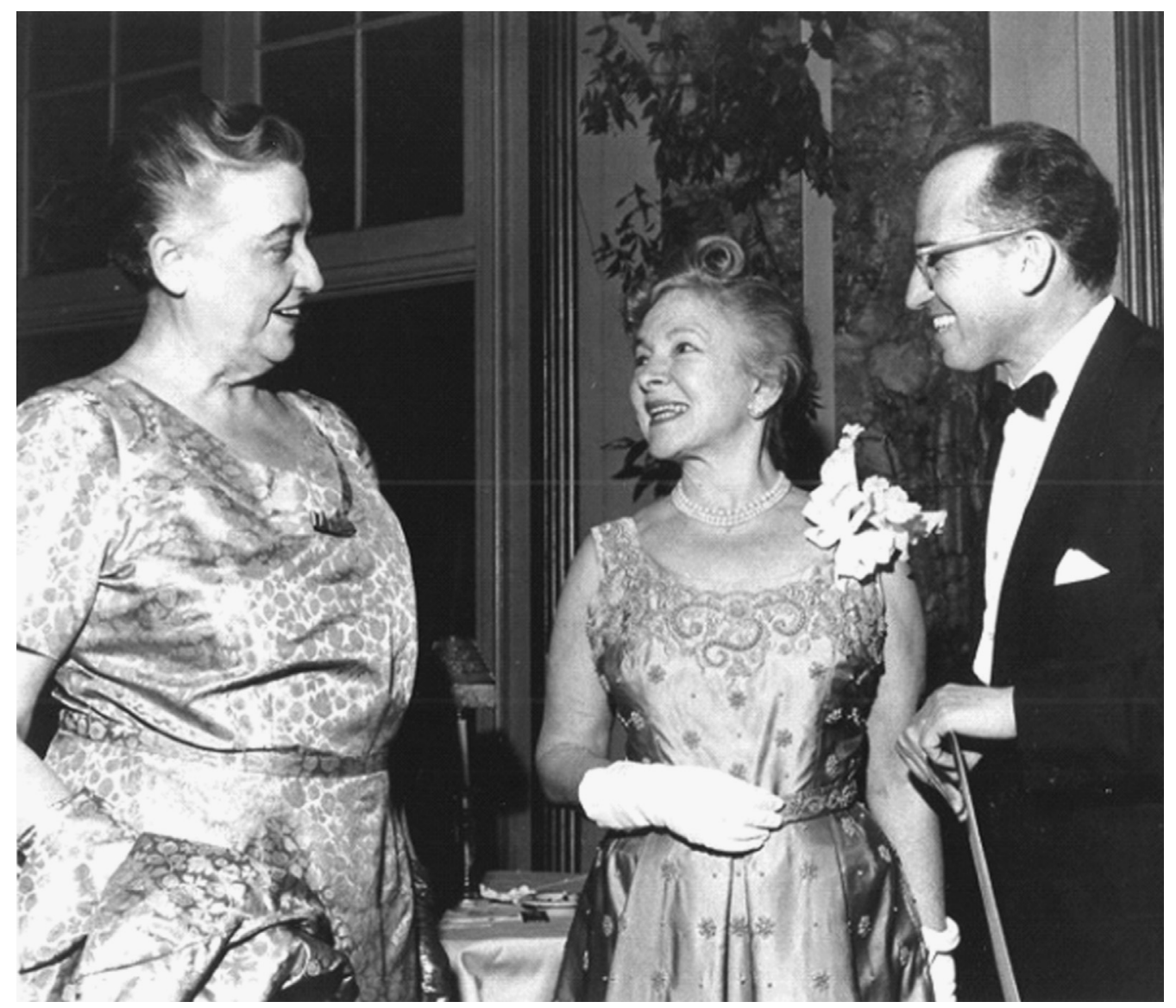

Figure 2. Dr Wright (left) and Dr Jonas Salk (right), with the American actress, Helen Hayes (center). Courtesy of Susan L. Whitney, University of Pittsburgh. 
annual conferences with Meyer Perlstein, MD, a pediatrician recognized as an expert in childhood neuromuscular disorders, through her association with the American Academy of Cerebral Palsy (now known as the American Association for Cerebral Palsy and Developmental Medicine) [8].

Pediatric PM\&R has always been a recognized specialty component within $\mathrm{PM} \& \mathrm{R}$ practice, and first-generation physiatrists, for example, George Deaver, MD [9], were specialists in the care of children with disabling conditions. Prominent second-generation physiatrists, such as Ernest W. Johnson, MD (electrodiagnosis), and Frederick Kottke, MD (neurophysiology of motor function and motor control), are recognized for their expertise and contributions in adult PM\&R but also made contributions to pediatric PM\&R early in their careers. In the 1970s, physiatrists with an interest in pediatric rehabilitation advanced the field through educational programs and network opportunities at national meetings of the American Academy of Physical Medicine and Rehabilitation (AAPM\&R), and through pre-annual assembly activities beginning in 1979. This group eventually grew to become the Pediatric Rehabilitation Special Interest Group in 1983, one of the first AAPM\&R Special Interest Groups. The Pediatric Rehabilitation/Developmental Disabilities Council is now 1 of 5 councils within the AAPM\&R. Despite the relatively small numbers of physiatrists who claim pediatric $P M \& R$ as a primary focus of practice or research, these physiatrists are as passionate about the subspecialty as Wright was many decades before.

\section{THE POLIOMYELITIS EPIDEMIC: INTERVENTION, INVENTION, AND GLOBAL HEALTH}

The poliomyelitis epidemic extended over decades, beginning in the 1920s [10], and the associated morbidity and mortality reached an all-time high in 1952 [6]. As a physician leader in a number of Pittsburgh medical institutions, Wright participated in the acute care management of poliomyelitis, and the directorship position at the D. T. Watson Home allowed her to continue rehabilitation interventions for those patients with residual disabilities, including profound paralysis with respiratory complications. Dedicated to finding medical interventions to prolong life and enhance function, Wright took on the challenge by inventing a device, the Respir-Aid rapid rocking bed, for patients with these complications. The bed is mounted on rockers, electrically powered to adjust rocking from 12-26 times per minute, and modified to support the patient during the rocking motion. It takes advantage of gravity to move the viscera against and away from the diaphragm to allow air exchange. The rocking bed was first used successfully in 1944 [11] and facilitated weaning of many children and young adults from iron lungs to regular hospital beds and increased the possibility of their returning home. Nursing care needs were addressed and skin care improved because patients could now be turned. Therapeutic activities such as range of motion were facilitated because limbs were more accessible to therapists (Figure 3). Wright also had a novel idea of combining the use of a chest "cuirass" with the rocking bed to maximize activity of the respiratory system (Figure 4). The cuirass is a method of biphasic respiratory support and consists of a hard shell that fits over the anterior chest and is attached to a pump. Pumping air out around the chest creates negative pressure for inspiration, and positive pressure is created for expiration by pumping air into the area around the chest. Wright's understanding of respiratory physiology established the basis for timing the negative pressure, applied as the foot of the bed descended, so as to maximize inspiratory assistance (slides developed for Jessie Wright presentations, circa 1950s, courtesy of M.A.). A company in Toledo, Ohio, began fabricating Wright's invention, and its effectiveness was documented in a 1947 publication in the American Journal of Nursing [12].

Salk began his important work on the polio vaccine in Pittsburgh [6], and Wright and her inpatient programs were important to his success. She and her staff introduced an abridged manual muscle test for classifications of motor impairments and used sequential examinations of immunized patients to detect vaccine effects on motor strength as well as provide evidence for a diagnosis of polio [13]. Wright believed that range of motion was the foundation for all functional movement and that full range of motion would allow for the use of residual muscle power and the utilization of assistive and adaptive devices before and after maximal recovery. She had an interest in the use of curare as a preparation for avoidance of severe pain triggered by stretching, especially in the acute phase of polio [14]. Wright provided access to patient populations for Salk to obtain convalescent titers from patients' initial exposure and subsequent levels, after receiving the vaccine, and this was key information required for further development of the vaccine [6].

\section{NATIONAL LEADERSHIP AND RESEARCH}

Wright served as a medical consultant to the Pittsburgh Department of Health from 1942-1956 and as a consultant to the surgeon general of the U.S. Air Force from 1950-1953. She represented the National Foundation for Infantile Paralysis at a severe outbreak of poliomyelitis in Argentina in 1956. Wright provided education about acute care, rehabilitation, and long-term care during her time in Argentina and was recognized by the Argentine government and the U.S. State Department for her work there. Throughout her career, she provided consultation to more than 20 rehabilitation centers worldwide. (Figure 5). She was a founding member of the U.S. Committee of the International Society for the Welfare of "Cripples," with a certificate signed by Henry Kessler, MD, in 1952 [4]. Wright's interest in the rehabilitation of injured veterans led her to work as a consultant to the U.S. Air Force during the Korean War. As a 


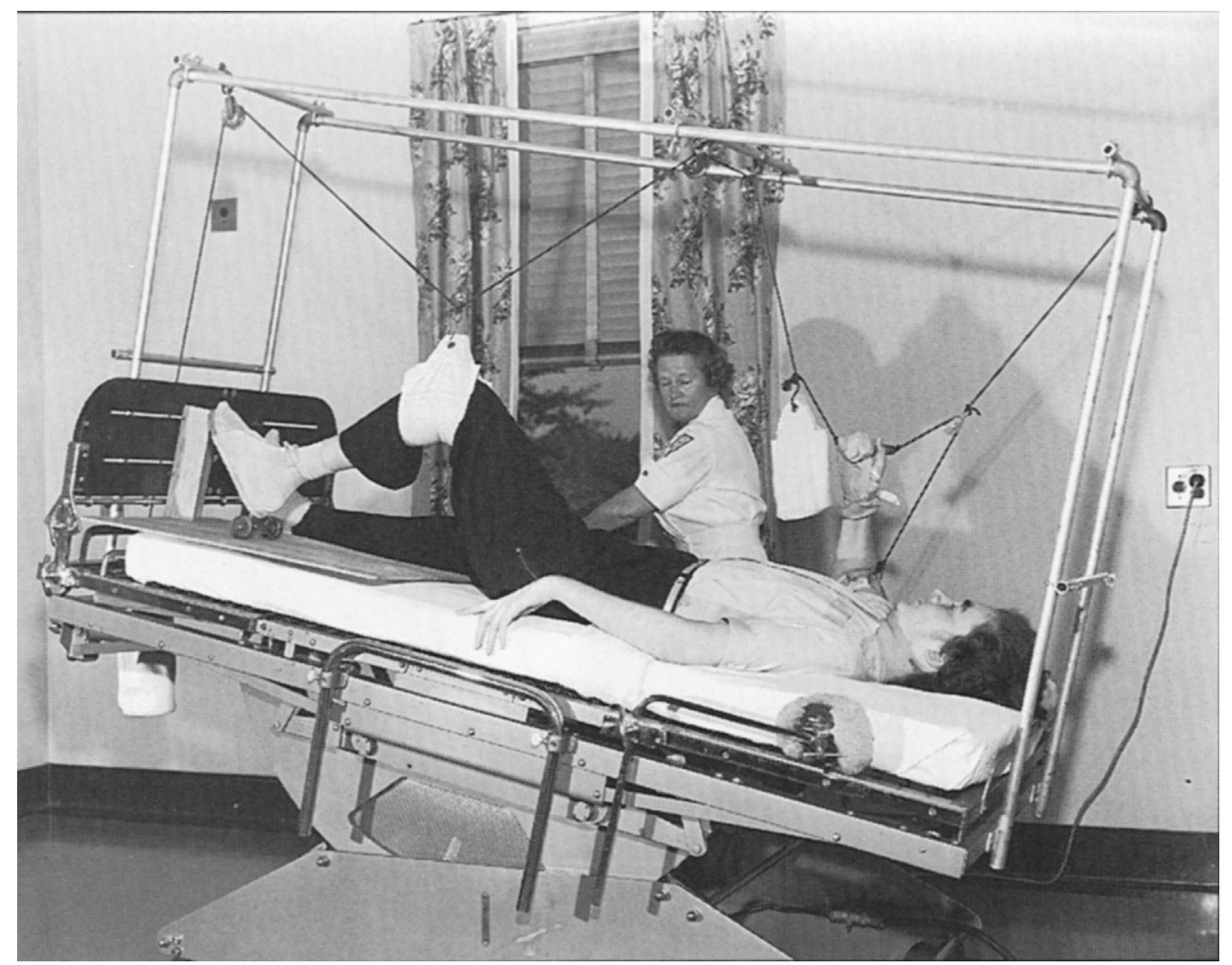

Figure 3. Therapy was performed while using the rocking bed for respiratory support. This invention was an advancement for rehabilitation because the iron lung (more typically used) limited access to limbs for ranging and strengthening. Courtesy of Michael Alexander, MD, Thomas Jefferson University.

consultant, she provided advice concerning education and employment opportunities for individuals who had sustained significant disabilities during combat.

In 1962, Wright became president of the American Association for Cerebral Palsy and Developmental Medicine and received the Outstanding Merit Award from United Cerebral Palsy that same year. She served on the board of trustees of Goodwill Industries in Pittsburgh, and, in 1958, she received an award for contributions to the development of effective educational services for students with "handicaps" within public schools in the Commonwealth of Pennsylvania [4].

Wright authored several articles about aspects of patient care that are still relevant today, including acute management, nutrition, nursing care, and therapy interventions [12,14-17]. She promoted the use of medications to enhance vascular flow or to promote relaxation of muscles and physical therapeutic interventions, such as electrical stimulation, mobilization, massage, muscle re-education, aquatics, and orthotics. In addition, she was an advocate of psychology, therapeutic recreation, and occupational therapy, all disciplines focused on an ultimate goal of promoting independence for patients with disabling conditions. Her interests and research touched the full spectrum of PM\&R: outcome and diagnostic measurement tools, intervention strategies, and inventions to promote function and quality of life and prevention of disability. She was the editor of "Physical Medicine and Rehabilitation" in the Cyclopedia of Medicine, Surgery, and Specialties series, from 1946-1949 [4]. Her areas of research, service, and publications encompassed arthritic conditions, cerebral palsy, and, most notably, poliomyelitis.

Wright received the Woman of the Year award in Pittsburgh in 1950 and again in 1968. She was named a Distinguished Daughter of Pennsylvania, and the Medical Woman's Association named her Medical Woman of the Year in 1954. She also was named an honorary member of the American Physical Therapy Association in 1960 because of her contribution to the education of professionals concerning the care of people with disabilities. She served on the board of trustees for the University of Pittsburgh [18].

\section{HISTORIC ACHIEVEMENTS FOR A WOMAN PHYSICIAN}

Wright's accomplishments must be placed in a historical context, and, in this context, these accomplishments become even more significant. Women were not admitted to the American Medical Association until 1915 [19], and the American Medical Association did not have a woman board 


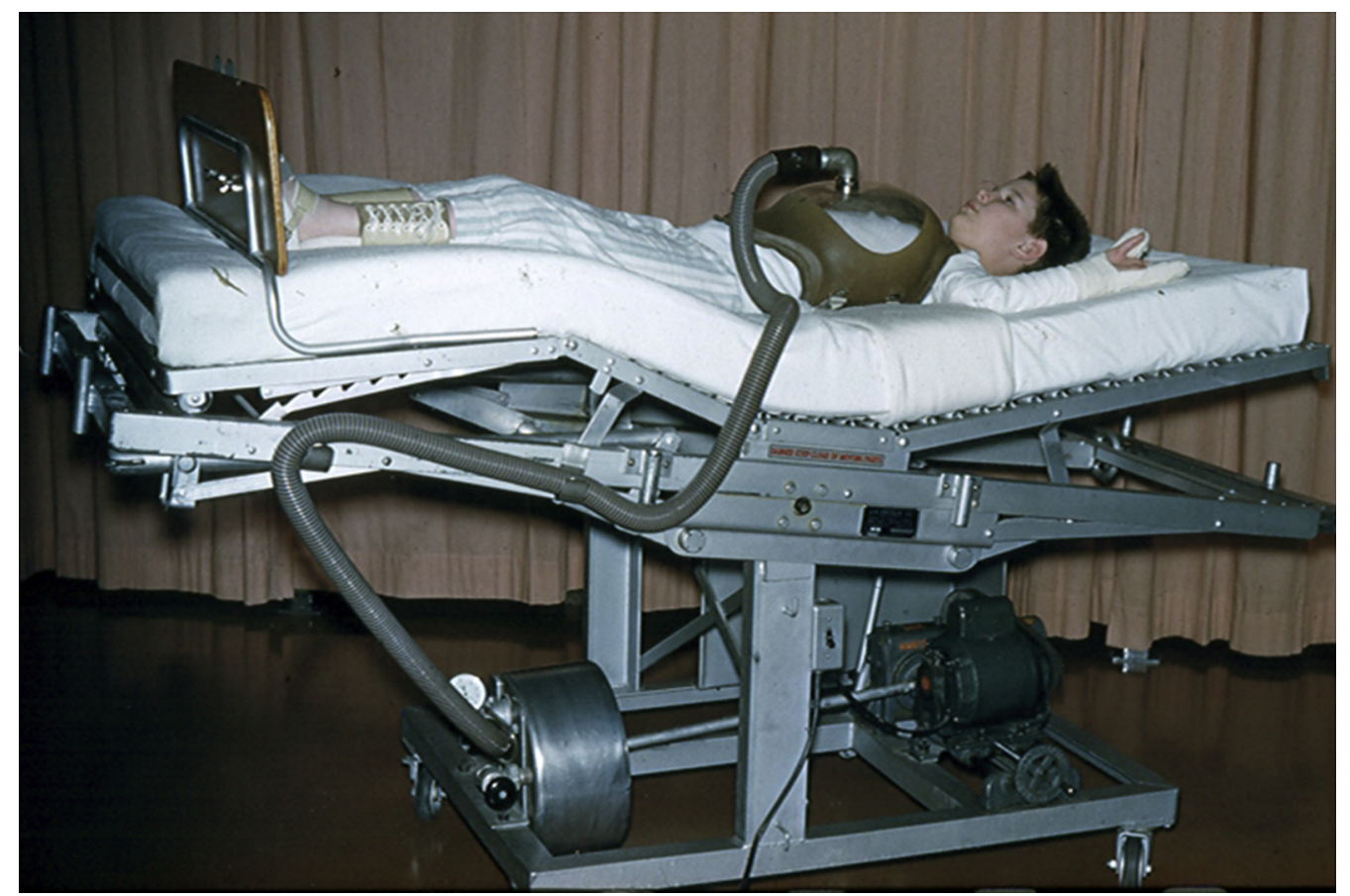

Figure 4. Wright promoted the use of the rocking bed with the chest cuirass for respiratory support. Courtesy of Michael Alexander, MD, Thomas Jefferson University.

member until 1989 or a woman president until 1998 [20]. In 1944 , 21\% of U.S. hospitals had never employed a woman intern [19]; in 1956, only 5.3\% of medical students were women [21]. The number of women leaders in academic medical centers remained low throughout the 20th century, and, even in 1995, only $11 \%$ of full professors were women. This figure increased to only 20\% in 2012 [22].

In the field of $\mathrm{PM} \& \mathrm{R}$, the statistics are comparable. Although, in contrast to other medical specialties, PM\&R started out on a high note by electing a woman president, Frances Baker, MD, in 1951, just a few years after the specialty of PM\&R was recognized. However, the next woman president of the AAPM\&R was elected 38 years later, in 1989. Since 2000, the organization has now had 3 women presidents. The percentage of women residents in PM\&R is now similar to the percentage of women in medical school, that is, approximately 40\% (Karen Mathias, ABPMR, oral communication, June 2013) but lagged behind just a decade ago [22]. Recent surveys of AAPM\&R membership suggest that the numbers of women in the AAPM\&R rose slowly over the past decade, and women are now approximately one-third of the total membership (Joanne Constantine, communications director, AAPM\&R, e-mail communication, June 2013). Of the top awards presented by AAPM\&R, such as the Krusen Lifetime Achievement award and the Zeiter lectureship, only 15\% have been granted to women [23].

These numbers are only marginally higher than those of women who achieved full professor rank in academic medicine $[24,25]$. A recent survey of pediatric physiatrists suggests that the subspecialty is quite heavily composed of women (71\% of those surveyed); however, female respondents earned only approximately $82 \%$ of the compensation of male respondents [26]. Within other PM\&R organizations, the first woman president for the Association of Academic Physiatrists was elected in 1971 (Lawrence C. Pencak, executive director, Association of Academic Physiatrists, oral communication, June 2013). The first woman chair of the ABPMR was elected in 2005. (Donna Morgan, ABPMR, oral communication, June 2013). Wright overcame many barriers through her intelligence and her pursuit of excellence and perhaps because of other unidentified factors. In any case, she certainly led the way in pediatric $P M \& R$ and for women in $\mathrm{PM} \& \mathrm{R}$, and her legacy must not be forgotten.

\section{THE LATER YEARS}

After her retirement, Wright was active in her community through church and civic activities. She died in 1970 at the age of 70 [18]. Comments from members of the D. T. Watson Board of Directors, former colleagues, former patients, and older family members of D. T. Watson patients are evidence of the institutional memory and testimony that her contributions live on. Many note that she was strong and assertive, brilliant, and truly respectful and caring of her patients and their families. Her tall, imposing figure may have been initially intimidating, but she very quickly made 


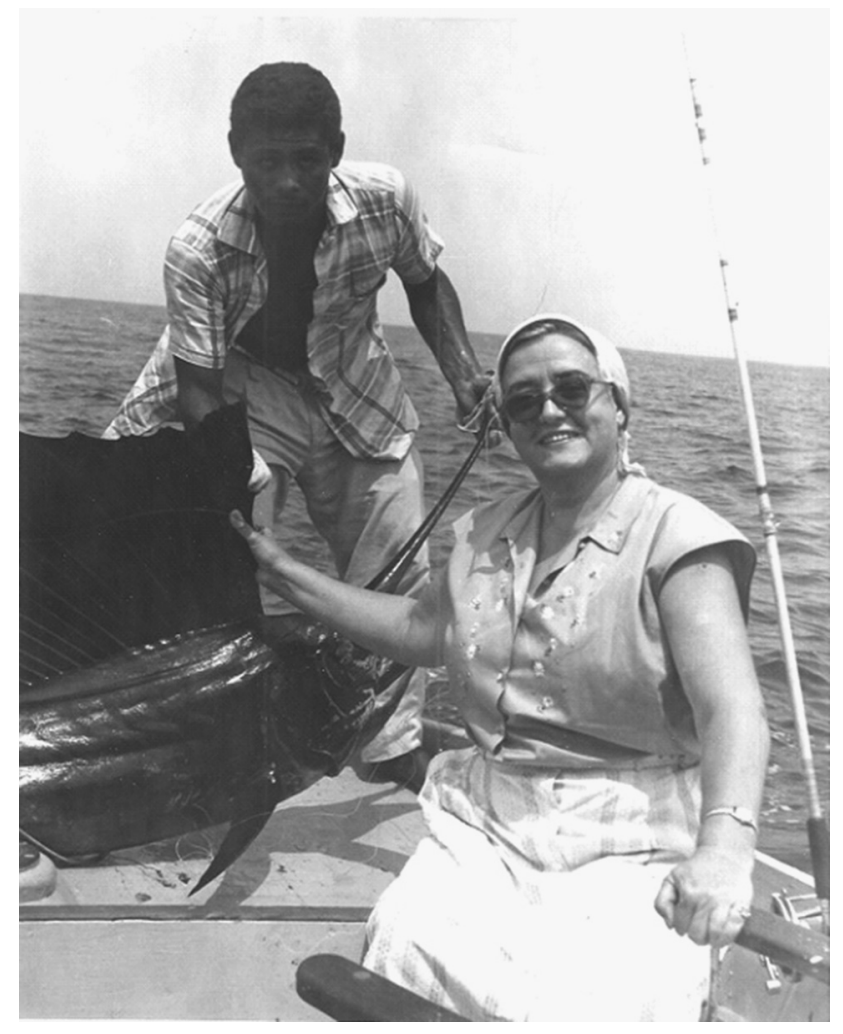

Figure 5. While in Mexico presenting her work at the Pan American Medical Congress in 1960, Wright caught a sailfish and had it mounted in the aquatics area at D. T. Watson. Courtesy of Susan L. Whitney, University of Pittsburgh.

those under her care feel secure and comfortable. Many of her adaptive walkers and aids for patients with polio and cerebral palsy were still in use at the D. T. Watson Home well into the 1980s. The School of Physical Therapy at the University of Pittsburgh also recognizes her to this day (Michael Alexander, MD, personal communications with the members of the Pittsburgh medical community, Watson Board, and former patients, when he served as medical director at D. T. Watson, from 1979-1986).

\section{CONCLUSION}

Wright made countless contributions to both PM\&R and pediatric PM\&R during many decades of medical practice. She advanced the specialty of PM\&R and the subspecialty of pediatric PM\&R during its earliest years. She had a national and an international reputation for collaboration and teaching in presentations, publications, and public service. She was remarkably successful at a time when women represented a small minority of physicians. Despite many obstacles, Wright succeeded by virtue of her intelligence, her many talents, and her drive to build, to invent, and to innovate. It is likely that she accomplished even more because of a keen appreciation of the need to develop, sustain, and benefit from key professional relationships throughout a long career.

\section{ACKNOWLEDGMENTS}

We thank the following individuals: John F. Ditunno Jr, MD, for his enthusiasm regarding this biography and help in obtaining resource material; Susan L. Whitney, PT, PhD, University of Pittsburgh, professor, physical therapy, and associate professor in otolaryngology, School of Health and Rehabilitation Sciences, for her assistance in obtaining Ms Lucille Cochran's documents and photographs; Tracy L. Burr, CAE, executive director, American Academy of Cerebral Palsy and Developmental Medicine for her assistance in documenting Wright's role in the American Association for Cerebral Palsy and Developmental Medicine; and M. Elizabeth Sandel, MD, for her editorial assistance.

\section{REFERENCES}

1. Turk MA, Mudrick N. Rehabilitation interventions. In: Albrecht GL, ed. SAGE Reference Series on Disability: Key Issues and future Directions. Thousand Oaks, CA: SAGE Publications; 2013.

2. Luft E. Elizabeth Blackwell at Geneva Medial College: Reflections on the 150th anniversary of women in medicine. Watermark (Arch Libr Hist Health Sci) 1999;22:73-81

3. Hudak AE, Sandel ME, Goldberg G, Wrynn A, Frances A. Hellebrandt, MD. Pioneering physiologist, physiatrist, and PM\&R program innovator. PM R 2013;5:639-646.

4. Cochran L. Preparation notes, multiple biographies, Curriculum Vitae, prepared 1952-1970. Courtesy of Dr. Susan Whitney, University of Pittsburgh, Professor in Physical Therapy and Associate Professor in Otolaryngology, School of Health and Rehabilitation Sciences; archived at University of Pittsburgh, School of Health and Rehabilitation Sciences.

5. Wright J. Application for ABPM, 1947. Courtesy of ABPMR; archived at ABPMR offices, Rochester MN.

6. Oshinsky D. Polio: An American story. New York, NY: Oxford University Press; 2005.

7. Wright J. The prescription of physical therapy. Physiotherap Rev 1946 26:168-173.

8. American Association for Cerebral Palsy and Developmental Medicine, 1996 Final Program from the Annual Meeting held in Minneapolis MN, 50th Anniversary Edition, courtesy of AACPDM; archived at Developmental Medicine and Child Neurology offices, Milwaukee, WI.

9. Flanagan SR, Diller L. Dr. George Deaver: The grandfather of rehabilitation medicine. PM R 2013;5:355-359

10. Gould T. A Summer Plague: Polio and Its Survivors. New Haven, CT: Yale University Press; 1995.

11. Stanley A. Mothers and Daughters of Invention. Notes For A Revised History of Technology. New Brunswick, NJ: Rutgers University Press; 1995.

12. Wright $J$. The Respir-Aid rocking bed in poliomyelitis. Am J Nurs 1947;47:454-455.

13. Dreeben $O$. Introduction to Physical Therapy for Physical Therapist Assistants. Sudbury, MA: Jones and Barrtlett Publishers; 2007.

14. Wright J. Physical and occupational therapy in poliomyelitis. Pediatr Clin North Am 1953;1:26-34.

15. Wright J. Diet in relation to poliomyelitis. Public Health Nurs 1946;38: 345-348. 
16. Wright J. Factors related to prescription in poliomyelitis. Physiotherap Rev 1947;27:227-231.

17. Wright J. Early treatment of poliomyelitis. AMA Am J Dis Child 1954; $87: 354-360$

18. Rehabilitation Expert Dr. Jessie Wright. Obituary. Pittsburgh PostGazette, September 7, 1970 Obituary. Available at http://news.google. $\mathrm{com} /$ newspapers $?$ nid $=1129 \& \mathrm{dat}=19700907 \& \mathrm{id}=\mathrm{nH}$ IAAAAIBAJ $\&$ sjid=3WwDAAAAIBAJ\&pg=7114,947615. Accessed June 24, 2013.

19. Heins M. Women in medicine: A historical perspective. Internist 1986; 27:7-9.

20. Wolfe CV. Women in medicine: An unceasing journey. Arch Phys Med Rehabil 2005;86:1283-1286.

21. McGrew EA. The history of women in medicine: A symposium (the present). Bull Med Libr Assoc 1956;44:23-24.
22. More ES, Greer M. American women physicians in 2000: A history in progress. J Am Med Womens Assoc 2000;55:6-9.

23. Past $A A P M \& R$ Award Recipients. The Frank $H$. Krusen, MD, Lifetime Achievement Award Recipients. Available at http://www.aapmr.org/ members/activities/awards/Pages/AAPMR-Award-Recipients-.aspx.

Accessed June 25, 2013.

24. Wong E, Cardenas DD. Women in physical medicine and rehabilitation- leadership issues. Phys Med Rehabil Clinic N Am 2001; 12:1-7.

25. Nonnemaker L. Women physicians in academic medicine: New insights from cohort studies. N Engl J Med 2000;342:399-405.

26. Houtrow A. Results from the 2009 Pediatric Rehabilitation Practice survey of the AAPM\&R Pediatric Rehabilitation/Developmental Disabilities Council. PM R 2011;3:45-52. 